\title{
CRIAÇÃO INTELECTUAL EM CURSOS DE DESIGN: autoria e titularidade
}

\author{
Hugo Borges Backx - DSc \\ Universidade Federal do Rio de Janeiro \\ backx@acd.ufrj.br
}

\begin{abstract}
Resumo: Diversas criações intelectuais provenientes de relações de trabalho podem ser protegidas pela Lei de Propriedade Industrial (LPI), que compreende um conjunto de normas que estabelecem direitos de propriedade do trabalho criativo em questão. Esta mesma ferramenta reguladora se aplica aos docentes cujo trabalho é supervisionar criações intelectuais em disciplinas, que, inerentemente, envolvem criatividade. Nos cursos de Design há disciplinas com este perfil gerando conteúdos criativos diversos por conta da relação entre docente e aluno. Contudo, o aluno não tem relação de trabalho nem com o docente e nem com a instituição de ensino, além de ser parte ativa no processo de geração desses conteúdos. $O$ aluno figura nessa relação como o beneficiário do serviço de ensino contratado com a instituição, sendo o docente o seu executor. A investigação das relações de autoria e titularidade dos conteúdos criativos acadêmicos em Design entre instituição de ensino, docente e aluno foi a contribuição do presente trabalho para aclarar essas relações. E, como contraponto, a norma da UFRJ que a colocou como a titular de toda criação em seu âmbito.
\end{abstract}

Palavras-chave: criação, propriedade intelectual, titularidade, autoria.

Abstract: Many intellectual creations originating from work relationships can be protected by the Industrial Property Law (IP) that comprises a collection of regulations that establish rights of ownership of the creative work in question. This same regulative tool applies to teachers whose job it is to supervise intellectual works in disciplines, which inherently involve creativity. In Design courses, there are disciplines with this profile that generate diverse creative content, which results from the relationship between the teacher and the student. The student, however, does not have a work relationship with either the teacher or the school other than in the process of actively creating original designs. In this relationship, the student is the beneficiary of the teaching services provided by the school; and the teacher performs those services. The investigation of the relations of authorship and ownership of to academic creative content in Design between the school, the teacher, and the student was the contribution of the present review with the aim of clarifying these relationships. As a 
counterpoint to the rule of the Universidade Federal do Rio de Janeiro (UFRJ) that give it ownership of to all creative content initiatives within its walls.

Keywords: creation, intellectual property, ownership, authorship.

\section{INTRODUÇÃO}

Através da exteriorização da criação intelectual é que terceiros tomam ciência do teor criativo contido numa determinada obra criada, através dos seus contornos ou limites manifestados ou fixados em algum suporte. Esta exteriorização ou delimitação da criação é distinta do plano das ideias do criador que livremente a constrói e a reconstrói num processo criativo interno complexo (MARTíNEZ, 2003).

A imaterialidade é uma característica do conteúdo criativo. Para ser delimitado precisa ser expressado ou fixado em algum suporte tangível ou intangível. Segundo Bittar Filho (2004), são considerados suportes tangíveis, por exemplo: livro, pintura, escultura, etc., já uma obra coreográfica apresentada por um sambista no desfile de uma escola de samba é considerada como intangível.

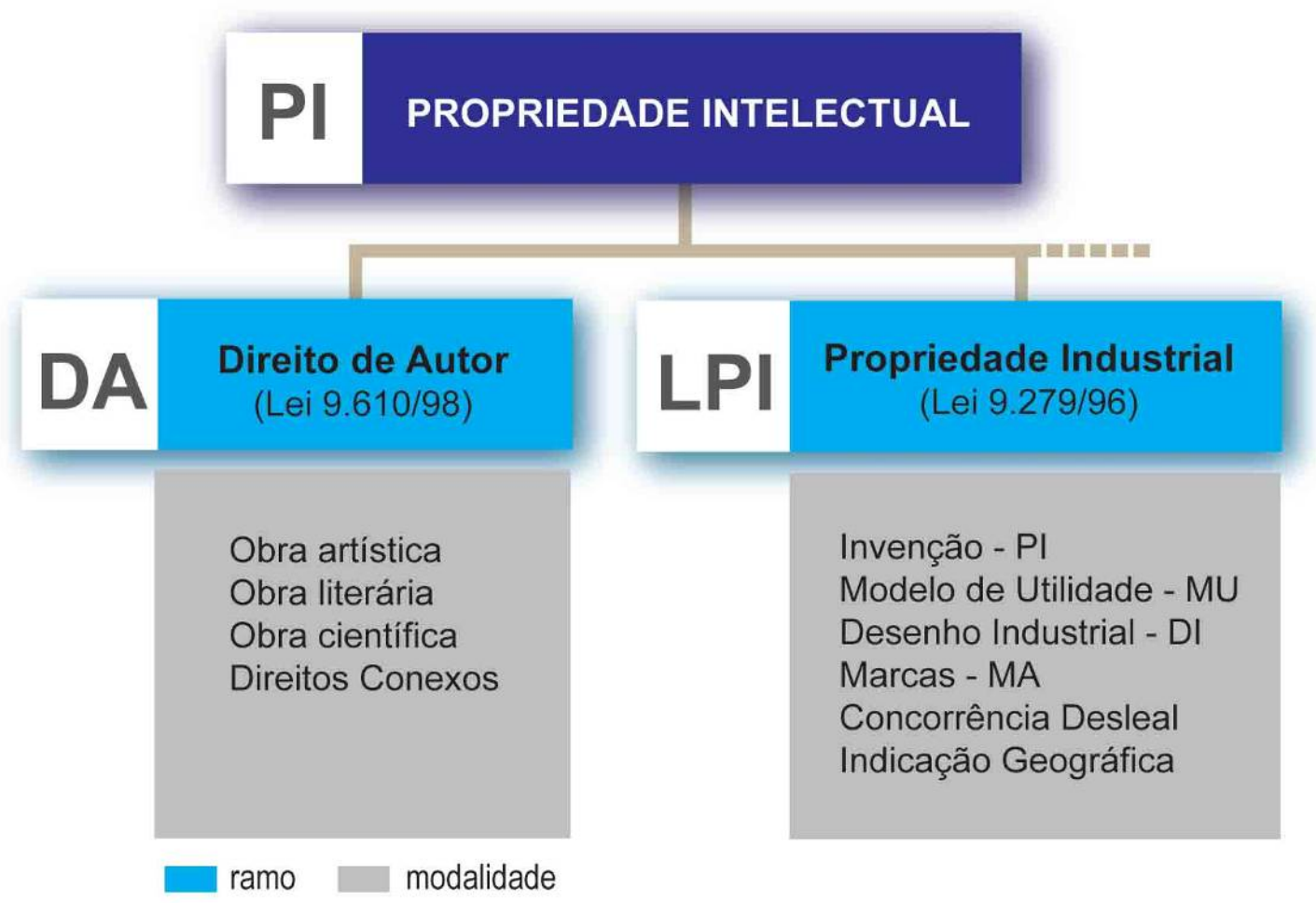

Figura 1 - Ramos da PI que têm relação com o Design.

(Fonte: Elaborada pelo autor com base na pesquisa realizada) 
A proteção e defesa de criações intelectuais, sejam elas de atributo estético ou técnico, faz-se através da Propriedade Intelectual (PI). Esta congrega diversas normas ${ }^{1}$, entre elas o Direito de Autor (DA) e a Lei de Propriedade Industrial (LPI) que são dois ramos da $\mathrm{PI}$ que alcançam conteúdos criativos gerados em Design. No DA o design pode ser amparado como obra artística, e na LPI como invenção, modelo de utilidade, desenho industrial ou marca (Figura 1).

O alcance de cada modalidade dessas dependerá, entre outros requisitos, do atributo do conteúdo criativo desenvolvido, podendo ser estético ou técnico. Quando for um conteúdo criativo estético, excluindo o aproveitamento industrial ou comercial das ideias contidas na obra ${ }^{2}$, poderá ser amparado pelo DA, e se é estético e tem aplicação industrial, ou com atributo técnico, poderá ser pela LPI (BACKX, 2013).

Pode acontecer também de um mesmo objeto criado ter mais de um conteúdo criativo incorporado (objeto híbrido) e, com isso, ser alcançado por mais de uma modalidade de um determinado ramo ou mesmo por mais de um ramo da PI. Como exemplos de objetos híbridos temos um pregador de roupas que foi protegido em duas modalidades diferentes do mesmo ramo, no caso, pela LPI: modelo de utilidade para o seu atributo técnico e desenho industrial para o seu atributo estético de aplicação industrial (Figura 2); e o anel Puzzle-Mix com proteção em dois ramos distintos: no DA como obra artística e na LPI como desenho industrial (Figura 2).

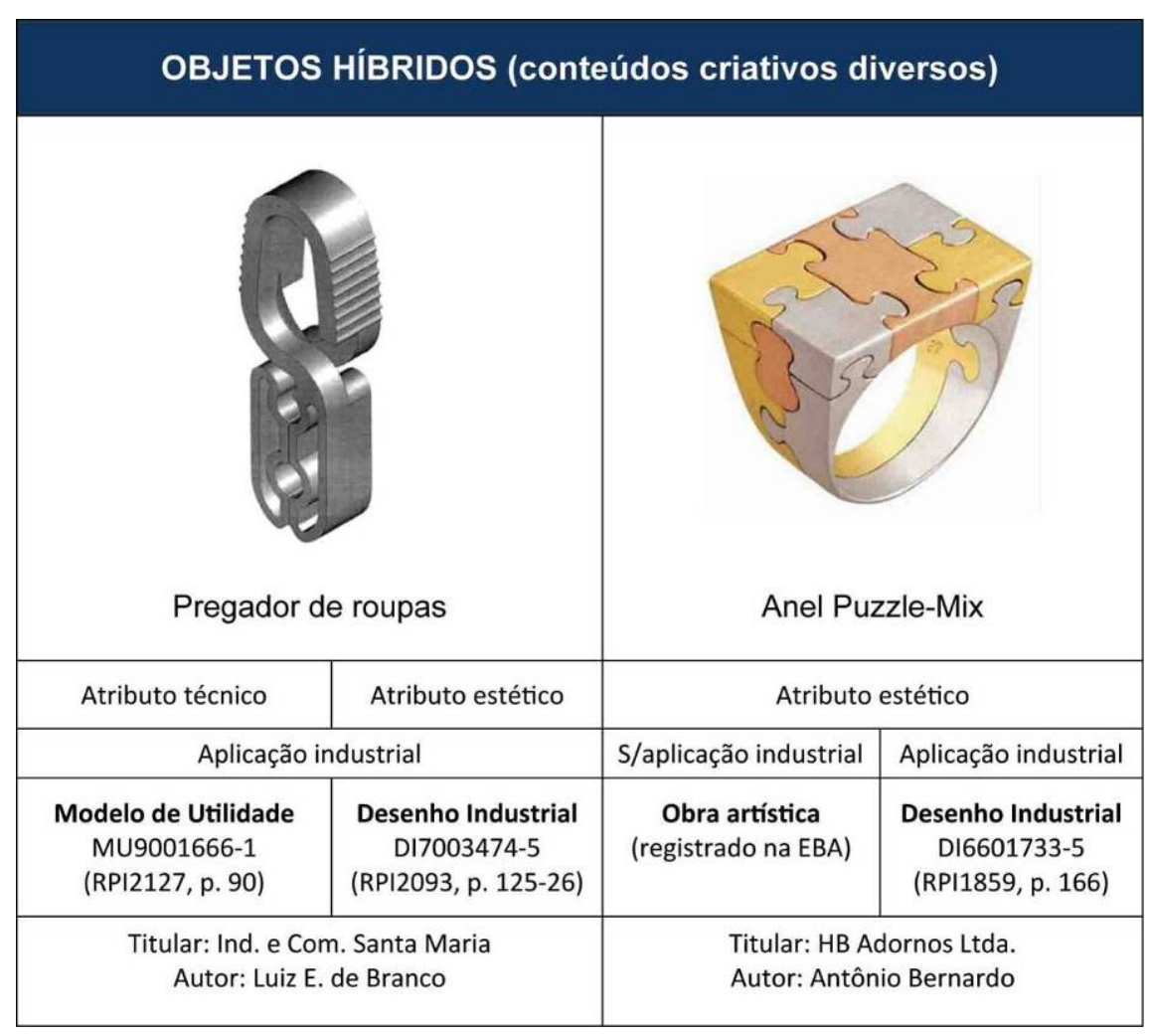

Figura 2 - Objetos híbridos (conteúdos criativos diversos).

(Fonte: Adaptada da Revista de Propriedade Industrial - RPI n²127, 2093 e 1859)

\footnotetext{
${ }^{1}$ Programa de Computador (Lei 9.609/98), Topografia de Circuito Integrado (Lei 11.484/07), Cultivares (Lei 9.456/97).

${ }^{2}$ Inciso VII, art. $8^{\circ}$, do DA.
} 
Outro aspecto da criação intelectual refere-se à sua titularidade, que deve ser entendida aqui como a propriedade da criação intelectual. O Direito de Autor (DA) estabelece quem tem a titularidade da obra coletiva, no caso, o seu organizador. Porém, é silente quando a criação ocorre dentro de uma relação de trabalho (emprego, estágio, etc.).

Diferentemente, a Lei da Propriedade Industrial (LPI) estabelece as regras para a identificação da titularidade das criações intelectuais nas relações de trabalho. São critérios diferenciados de apropriação da criação pelo empregador com o qual o contratado mantém alguma relação de trabalho, seja como empregado, autônomo (freelancer), estagiário ou bolsista. Para os casos de criações no âmbito do serviço público $^{3}$ ou com entidades públicas ${ }^{4}$, há normas próprias definindo titularidade, percentual de premiação, etc.

Na pós-graduação quando o conteúdo da criação intelectual se origina a partir de instrumentos de fomento (bolsas ou auxílios) do Conselho Nacional de Desenvolvimento Científico e Tecnológico (CNPq), sujeita-se a uma Resolução Normativa (RN 013/2008). Nela é indicado para quem o Conselho cederá a parte que Ihe cabe da titularidade e qual o percentual máximo nos ganhos econômicos quando do repasse ou do licenciamento das criações intelectuais desenvolvidas.

Nessa mesma linha de regulamentação da atribuição de direitos sobre criações intelectuais, baixou a Universidade Federal do Rio de Janeiro (UFRJ) uma Resolução ${ }^{5}$ em que se declara a titular dos direitos de propriedade intelectual das criações geradas em suas instalações e/ou com a utilização de seus recursos (art. 3ํ)), sejam elas desenvolvidas na graduação ou na pós-graduação.

Diante desse cenário normativo diverso como ficam as criações intelectuais oriundas das atividades acadêmicas nos cursos de Design? Quem poderá ser o titular ou autor ou coautor ${ }^{6}$ dessas criações?

\section{DESENVOLVIMENTO}

Em cursos de Design são gerados diversos conteúdos criativos quando do processo de ensino-aprendizagem, resultado de trabalho intelectual individual ou em grupo. $O$ que a presente pesquisa investiga são questões relativas à autoria e titularidade de trabalhos acadêmicos com conteúdos criativos.

No presente trabalho foram investigados os vínculos entre instituição de ensino, docente e aluno para identificação da titularidade e autoria das criações intelectuais quando realizadas em disciplinas de conteúdos criativos que utilizem instalações e/ou recursos disponibilizados pela instituição de ensino na realização das tarefas acadêmicas.

$\mathrm{Na}$ investigação foi utilizado como referencial principal a Lei de Propriedade Industrial (LPI) no que tange a titularidade das criações intelectuais realizadas por empregado, prestador de serviço ou estagiário ${ }^{7}$. Foram utilizadas também

\footnotetext{
3 Parágrafo único, art. 93, da LPI, Decreto no 2.553, de 16/04/1998, e Lei n 10.973, de 2/12/2004.

${ }^{4}$ Ex.: Resolução Normativa 013/2008, do CNPq (Conselho Nacional de Desenv. Científico e Tecnológico).

${ }^{5}$ Resolução n 1 CEPG, publicada no BUFRJ n 19, de 12/05/2011.

${ }^{6}$ Coautoria: obra criada em comum, por dois ou mais autores (item "a", inciso VIII, art. 5o, do DA).

${ }^{7}$ arts. 88 a 93 e 121, da LPI.
} 
experiências pessoais fruto das orientações em disciplinas de projeto e de projetos de final de curso realizadas no Curso de Desenho Industrial, Habilitação de Projeto de Produto, da Universidade Federal do Rio de Janeiro (UFRJ). Assim como, das orientações para alunos e docentes em Propriedade Intelectual através do Laboratório de Propriedade Intelectual (Lapi), da UFRJ.

A partir do resultado dessa primeira investigação foram realizadas algumas reflexões sobre a adequação da norma aprovada pela Universidade Federal do Rio de Janeiro, anteriormente citada, que estabeleceu novas relações de titularidade na instituição.

\subsection{Da titularidade da criação intelectual segundo a LPI}

Inicia-se a investigação a partir da questão da titularidade de criações intelectuais nas relações de trabalho definida pela LPI. É um conteúdo importante na gestão da criação intelectual seja para quem será titular da própria criação ou quando a desenvolver para terceiros. O resultado do trabalho intelectual criativo em design pode sofrer maneiras diferentes de apropriação ou titularidade de acordo com o tipo de relação de trabalho firmado com terceiros, pois a propriedade de uma determinada criação pode não estar automaticamente vinculada ao seu criador e, como consequência, não dispô-la livremente. Assim, o vínculo de trabalho pode alterar o quadro de titularidade do bem criado (VIVEIROS, 2010).

Todavia, independentemente de quem seja o titular da criação (proprietário), o nome do criador da obra intelectual deve permanecer relacionado à obra criada. Deve constar dos documentos quando de pedido de patente ou de qualquer registro em que se peça a identificação do autor. Este é um direito que não se transfere (direito moral). A vinculação entre a criação intelectual e o seu legítimo criador é permanente. Somente a propriedade é negociada, transferida, cedida, licenciada, etc.

A LPI, ao regular quem é o titular da criação intelectual numa relação de trabalho (limitado à invenção, modelo de utilidade e desenho industrial), o faz a partir das seguintes referências:

(i) se a criação intelectual tem relação ou não com a atividade contratada; e

(ii) se não tiver relação, se houve uso de qualquer recurso da empresa.

A partir desses dois referenciais principais, temos as seguintes possibilidades de titularidade (Quadro 1):

a) Para a criação intelectual oriundas diretamente da atividade profissional contratada, a titularidade é integralmente do empregador (art. 88, da LPI);

b) A criação intelectual não tem relação com a atividade profissional contratada mas houve a utilização de recursos da empresa, a titularidade é dividida igualmente entre o empregador e o autor do conteúdo criativo (art. 91, da LPI);

c) A criação intelectual não tem relação com a atividade profissional contratada e não houve a utilização de recursos da empresa, a propriedade é integralmente do autor (art. 90, da LPI). 
São regras de titularidade aplicáveis em qualquer relação de trabalho, embora novas regras possam ser estabelecidas por contrato ou norma.

Quadro 1: Titularidade da criação intelectual na relação de trabalho segundo a LPI.

(Fonte: Elaborado pelo autor com base na pesquisa realizada)

\begin{tabular}{|l|c|c|c|}
\hline \multicolumn{3}{|c|}{ TITULARIDADE NA RELAÇÃO DE TRABALHO - LPI } \\
\hline \multicolumn{1}{|c|}{ Vínculos } & \multicolumn{3}{|c|}{ Possibilidades de titularidade } \\
\hline \multirow{2}{*}{$\begin{array}{l}\text { Empregado } \\
\text { Autônomo }\end{array}$} & \multicolumn{2}{|c|}{ 1 - A criação intelectual resultou da atividade contratada? } \\
\cline { 2 - 4 } $\begin{array}{l}\text { Estagiário } \\
\text { Bolsista } \\
\text { Pesquisador }\end{array}$ & $\begin{array}{l}\text { SIM empregador é o } \\
\text { titular. }\end{array}$ & \multicolumn{2}{|c|}{ NÃO } \\
\cline { 2 - 4 }
\end{tabular}

\subsection{Relação entre instituição de ensino, docente e aluno para definição de titularidade e autoria da criação intelectual.}

Quando uma instituição de ensino é contratada por um aluno para prestar-lhe um serviço, esta contrata docente para executarem o serviço em seu nome. $O$ docente contratado quando do cumprimento do seu dever laboral, numa disciplina que determina a realização de conteúdos criativos, orienta o aluno para a realização da criação intelectual no processo de ensino-aprendizagem. $\mathrm{O}$ aluno, como o beneficiário do serviço contratado, utiliza-se dos recursos disponibilizados pela instituição contratada na realização da sua tarefa acadêmica estabelecida na disciplina.

Se dessa relação entre a instituição de ensino, docente e aluno resultar um conteúdo criativo: quem será autor e quem será titular da criação intelectual gerada?

Nos cursos de Design quando o docente é contratado para o exercício do magistério para uma disciplina com atividades criativas, e.g., disciplinas de projeto, com base nos critérios da LPI que define titularidade (Quadro 1), toda criação intelectual oriunda da sua atividade docente poderá a instituição de ensino ser a titular dela porque foi contratado para prestar um serviço objetivando a criação intelectual.

Quando as criações intelectuais desenvolvidas originam-se a partir da atividade docente em disciplinas que não se prevê atividade criativa, será preciso identificar se houve ou não a utilização de recursos da empresa para se definir a titularidade.

O aluno, entretanto, não mantém qualquer relação de trabalho com a instituição, ao contrário, ele é um tomador de serviço de ensino, seja ele privado ou público, e a instituição de ensino é quem tem de lhe prestar o serviço por força de um contrato firmado ou de dispositivos legais quando do acesso à instituição de ensino público.

Como a instituição de ensino é a prestadora de serviço que o realiza através de seu corpo docente, com base nos critérios de titularidade postos pela LPI ela não pode ser titular de qualquer criação intelectual do aluno, mesmo que este utilize os recursos 
da instituição, até porque são recursos que devem ser oferecidos a ele por força da própria prestação do serviço. Temos ainda a vinculação entre a necessidade de criação intelectual e disciplinas de conteúdo criativo, onde resultados criativos são objetivos a serem alcançados pelo aluno no processo de ensino-aprendizagem proposto pelo docente.

Outra relação é a do aluno com o professor orientador nas disciplinas de conteúdo criativo em que o exercício criativo é parte do objetivo dessas disciplinas. A atividade docente segue uma dinâmica de relação individualizada ou em grupo para se atingir tal objetivo, havendo troca de ações criativas entre todos para se chegar ao resultado criativo minimamente esperado, pois sem isto, o aluno provavelmente não lograria uma avaliação suficiente para a sua aprovação. $O$ ensino-aprendizagem de ações criativas voltadas para o desenvolvimento do trabalho acadêmico requer não só troca de conteúdos mas também de ações criativas entre o docente e o aluno em cada caso que orienta, objetivando alcançar um resultado satisfatório, sem, com isto, restringir a aprendizagem pessoal do aluno do processo criativo através da própria experiência criativa.

Dessa relação pode acontecer de o resultado da ação criativa apresentar alguma viabilidade econômica justificando a sua proteção via propriedade intelectual (PI). A questão é se o docente, no caso, pode ser considerado coautor dessa criação intelectual obtida numa disciplina de conteúdo criativo. Pela dinâmica de ensino anteriormente posta, uma vez que há troca de ações criativas objetivando o ensinoaprendizagem da criatividade na prática projetiva, parece que sim. Desse modo, toda criação realizada em sala de aula que demanda criatividade na obtenção do resultado acadêmico, o docente orientador também seria considerado coautor da obra realizada sob sua orientação.

Já em outros tipos de orientações acadêmicas (teses, dissertações ou monografias) que visam conteúdos teóricos ou práticos sem qualquer resultado intelectual criativo, a relação entre o orientador e orientando se mostra diverso das relações em orientações que objetivam a obtenção de criações intelectuais.

Nesse caminho, Denis Borges Barbosa (2009) entende que nas orientações, principalmente de teses, os orientadores não seriam coautores da obra realizada. 0 que se resguarda, no caso de obra científica, é o estilo do texto que descreve o conteúdo pesquisado e não o próprio conteúdo ${ }^{8}$. Mas se no resultado da pesquisa realizada houver conteúdo criativo passível de enquadramento em outros ramos da $\mathrm{PI}$, então o orientador poderá ser coautor na parte criativa pelo desdobramento do trabalho de orientação.

A Figura 3 mostra uma síntese do que foi até aqui analisado da relação de autoria e titularidade de conteúdos criativos entre aluno, docente e instituição de ensino. Sendo o aluno o beneficiário do serviço de ensino contratado; a instituição de ensino a prestadora do serviço de ensino contrato através do docente; e o docente, em nome da instituição de ensino, o executor do serviço, orientando o aluno para a realização da criação intelectual.

Quando discente e docente são autores por ações criativas em comum em disciplina de conteúdo criativo, a instituição de ensino será, por extensão, a titular da parte que cabe ao docente por força do contrato de trabalho que mantém com este,

${ }^{8} \S 3^{\circ}$, art. $7^{\circ}$, do DA. 
segundo as regras contidas na LPI. Ou seja, o aluno poderá ser autor e titular de uma obra criativa, já o docente será somente coautor quando derivar de atividade contratada pela instituição de ensino.

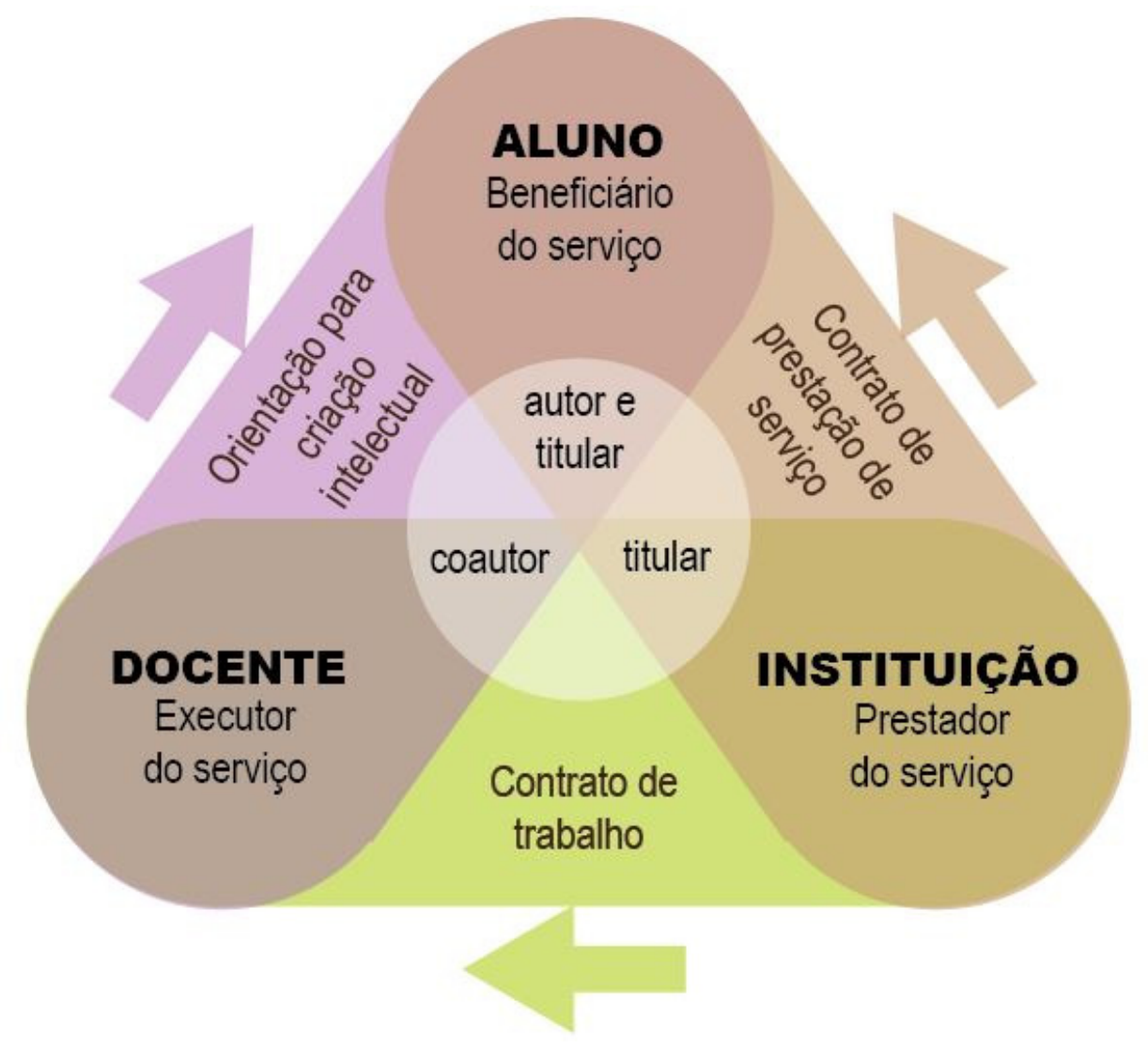

Figura 3: Relação entre aluno, docente e instituição de ensino.

(Fonte: Elaborada pelo autor com base na pesquisa realizada)

Essas relações também podem ocorrer em instituições públicas de ensino ${ }^{9}$. Contudo, há garantia legal ${ }^{10}$ ao docente de recebimento de um prêmio de até $1 / 3$ do ganho financeiro obtido pela instituição com a criação intelectual que tenha sido apropriada por ela. Diverso da iniciativa privada onde o empregado não tem direito a nenhuma outra retribuição financeira quando a criação derivar da atividade contratada, salvo se houver previsão contratual ${ }^{11}$.

\subsection{A titularidade das criações intelectuais na UFRJ}

Até recentemente as relações de autoria e titularidade entre alunos do curso de Desenho Industrial, habilitação Projeto de Produto, da Universidade Federal do Rio de Janeiro (UFRJ), quando encaminhados à Agência de Inovação da própria instituição,

\footnotetext{
${ }^{9}$ Para os docentes em regime estatutário não há contrato de trabalho.

${ }^{10}$ Parágrafo único, art. 93, da LPI, Decreto no 2.553, de 16/04/1998, e Lei n 10.973, de 2/12/2004.

${ }^{11} \S 10$, art. 88, da LPI.
} 
eram tratadas de modo que, caso houvesse interesse do aluno do curso em proteger alguma criação oriunda da atividade acadêmica, este teria de assinar um termo de cessão total dos direitos patrimoniais à instituição. Feita a cessão de direitos pelo aluno, a UFRJ figurava como a titular e o docente e o aluno como inventores no pedido de patente ou de registro ${ }^{12}$ (Imagem 1). Outras instituições públicas de ensino ${ }^{13}$ e privadas ${ }^{14}$ também protegeram as suas criações intelectuais, embora se desconheça aqui quais foram as políticas e sistemáticas de resguardo utilizadas por elas.

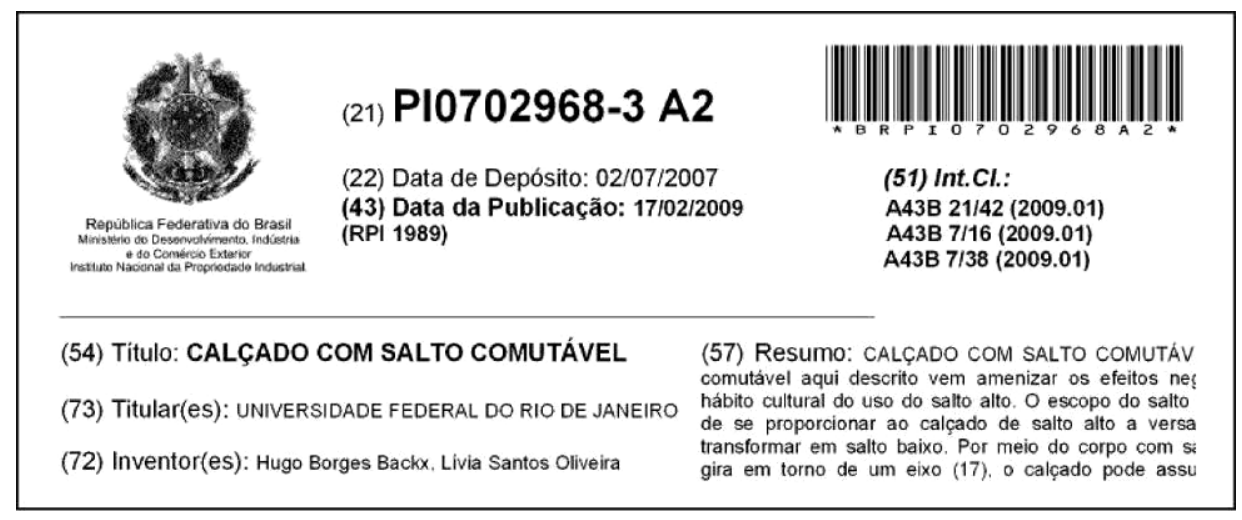

Imagem 1: Pedido de patente pela UFRJ.

(Fonte: adaptada do documento de patente $n^{\circ}$ BRPI0702968A2 do EPO - Espacenet)

Em 2011, a UFRJ mudou a sua sistemática de proteção das criações intelectuais e, através do seu Conselho de Ensino para Graduados (CEPG), aprova a Resolução CEPEG $n^{\circ} 1$, que estabeleceu novas relações de titularidade e fixou a parcela dos ganhos econômicos a serem auferidos. No tocante à titularidade, esta Resolução promoveu uma mudança significativa de posição da UFRJ diante das criações intelectuais desenvolvidas em seu âmbito. Destacam-se:

Art. 3o A Universidade Federal do Rio de Janeiro é a titular dos direitos de Propriedade Intelectual das criações geradas em suas instalações e/ou com utilização dos seus recursos por seus Criadores, segundo o disposto no Art. 4ㅇ․

$[\ldots]$

Art. 4을 Considerar-se-á Criação de titularidade da UFRJ quando for realizada por:

I. servidores docentes, técnicos e administrativos, que tenham vínculo permanente com a Universidade, no exercício de suas funções, ou que a sua Criação tenha sido resultado de atividades desenvolvidas nas instalações, ou com o emprego de recursos, dados, materiais, meios, informações ou equipamentos da UFRJ;

II. alunos e estagiários e seus orientadores que realizem atividades curriculares de cursos de graduação ou de pós-graduação na UFRJ, inclusive dissertações e teses desenvolvidas mediante o uso de instalações ou com o emprego de recursos, dados, materiais, meios, informações ou equipamentos da UFRJ (BUFRJ, 2011, p. 11, grifo nosso).

\footnotetext{
${ }^{12}$ Ex: DI6701910-2, DI6903234-0, DI6804417-8.

${ }^{13}$ Exemplos de registros de Desenho Industrial: UFMG: DI6902332-8, DI6702102-6, DI7001231-1; UFSC: DI6702565-0, DI6703046-7, DI6705260-6; USP: DI6504247-6; UFJF: DI6600663-5; UNB: DI6903392-7; UFU: DI7004420-1; UFOP: DI6502299-8; UESP: DI7102128-0

${ }^{14}$ Exemplos de registros de Desenho Industrial: UCS: DI6804255; UNISINOS: DI7005047; PUC-Rio: DI6804531-0, DI6905378-9, 6804438-0.
} 
Esta Resolução coloca a UFRJ como a titular de todas as criações intelectuais realizadas em seu âmbito. No caso dos servidores e estagiários, a regra acima, a princípio, não apresenta contradições em relação ao regramento contido na $\mathrm{LPI}^{15}$ (Quadro 1). O que se destaca da presente norma é a inclusão das criações de alunos oriundas de atividades curriculares com uso de recursos e/o instalações da instituição. O aluno, enquanto detentor do direito de receber um serviço público de ensino através dos recursos públicos disponibilizados para o cumprimento da obrigação legal da própria instituição, caso gere alguma criação intelectual resultante de atividade acadêmica, segundo a presente resolução, não será o titular da mesma. É a UFRJ a detentora de toda criação, independentemente de o aluno ser o tomador do serviço público e ela a prestadora do serviço.

Declara-se também titular de dissertações e teses (obras científicas), que são obras amparadas pelo DA onde não se resguarda o conteúdo científico ou técnico da obra em si, mas a forma como ele é descrito pelo autor:

No domínio das ciências, a proteção recairá sobre a forma literária ou artística, não abrangendo o seu conteúdo científico ou técnico, sem prejuízo dos direitos que protegem os demais campos da propriedade imaterial ( $§ 3 \circ$, art. 7으, do DA, grifo nosso).

A questão que se coloca é se a utilização de recursos e/ou instalações de uma instituição por parte de um autor de uma obra científica pode de fato contribuir de modo efetivo para a "forma literária ou artística" da mesma, ao ponto de justificar a instituição se declarar titular da obra, uma vez que o seu conteúdo científico ou técnico não é protegido pelo DA.

Da reflexão sobre este ponto, o que se observa é que recursos ou instalações ou orientações podem possibilitar a construção de conteúdos científicos ou técnicos, a "forma literária ou artística" como o autor expressa esses conteúdos na obra tende a ser associada ao seu estilo pessoal de escrever. Dessa reflexão, inclusive, há dúvidas da coautoria do orientador de obra científica, até quando este faz a revisão do trabalho orientado:

Não se considera co-autor [sic] quem simplesmente auxiliou o autor na produção da obra literária, artística ou científica, revendo-a, atualizando-a, bem como fiscalizando ou dirigindo sua edição ou apresentação por qualquer meio ( $\$ 1$, art. 15, do DA, grifo nosso).

Por outro, caso haja conteúdo científico ou técnico em obra científica realizada que seja passível de proteção por outros ramos da $\mathrm{PI}^{16}$ criam-se vínculos de coautoria do orientador e de titularidade da instituição e, dependendo do caso, de titularidade também do orientador, com esses conteúdos criativos gerados.

Ou seja, a UFRJ ao estabelecer uma forma única e ampla de apropriação das criações intelectuais sem considerar possíveis variações nas relações entre autores e instituição, como fundamentado neste trabalho com base no conjunto normativo da $\mathrm{LPI}$, e nem de características específicas das obras em si, como no caso das obras

\footnotetext{
${ }^{15}$ Quadro 1.

${ }^{16}$ Ex.: Propriedade Industrial (LPI), Programa de Computador, etc.
} 
científicas, pode gerar dificuldades em aplicá-la e até mesmo desestimular a criação intelectual do seu corpo social: docente, aluno e funcionário.

\section{CONCLUSÃo}

Nos casos específicos de cursos em que a atividade acadêmica é voltada para criações intelectuais como núcleo formador do aluno, e sendo este avaliado academicamente segundo os resultados criativos por ele obtidos na disciplina, este precisa necessariamente criar para obter alguma avaliação favorável na atividade acadêmica proposta. Não obtendo resultados criativos esperados na disciplina, as chances de uma boa avaliação ficam comprometidas, assim, a geração de conteúdos criativos pelo aluno quando da realização da atividade acadêmica é imprescindível.

Por outro lado, o docente contratado, quando do processo de ensinoaprendizagem, deve contribuir para que o aluno encontre os meios de alcançar um resultado criativo favorável na tarefa que lhe é demandada. Nesse processo de troca entre docente e aluno, quando da ação criativa, a aferição do quantum cada um cooperou para o resultado final apresenta alguma imprecisão pela dificuldade de se identificar em que grau cada informação ou ação contribuiu positivamente para o resultado criativo gerado.

Já a instituição de ensino é quem estabelece, através do seu Projeto Pedagógico, o perfil do egresso que deseja formar. Nos cursos de Design, independentemente de habilitação ou ênfase, o desenvolvimento da capacidade do aluno de responder de modo criativo aos desafios postos nas disciplinas é um primado norteador na formação do futuro egresso, visto que em Design a capacidade criativa é essencial para o exercício da atividade profissional.

Nesse processo criativo acadêmico surgem questões relativas à autoria e titularidade das criações intelectuais. Para respondê-las, um caminho foi interpretar as relações estabelecidas entre instituição de ensino, docente e aluno a partir do conjunto normativo contido na Lei de Propriedade industrial (LPI) que define os critérios para a titularidade das criações intelectuais na relação de trabalho. Desse conjunto normativo verificou-se o seu alcance na relação entre o docente e a instituição de ensino, mas não na relação entre aluno, instituição de ensino e docente.

Com os vínculos identificados entre os atores da relação, foi possível se chegar as prováveis autorias e titularidades de conteúdo criativo gerado a partir dessa relação. Ficando o aluno como autor e titular, o docente como coautor e a instituição de ensino como titular da parte que cabe ao docente em razão do que estabelece a LPI.

Já com uma sistemática diversa, a Resolução CEPG $n^{\circ} 1$ da UFRJ a colocou como a única titular de toda criação intelectual realizada em seu âmbito e que tenha se utilizado das suas instalações e/ou recursos. Portanto, outro entendimento dos possíveis alcances da titularidade sobre as criações intelectuais no campo acadêmico.

Como no Brasil existem vários cursos de Design, e neles são gerados diversos conteúdos criativos baseados nas mesmas relações aqui analisadas, sugere-se, como trabalhos futuros, a investigação de como ocorrem nas demais instituições de ensino as relações de autoria e titularidade das suas criações intelectuais, trazendo a lume a produção acadêmica e a forma como ela tem sido apropriada. 


\section{REFERÊNCIAS}

BACKX, Hugo Borges. Design e Propriedade Intelectual: vínculos e interações. 2013. 281 f. Tese (doutorado). Departamento de Artes \& Design. Pontifícia Universidade Católica do Rio de Janeiro.

BARBOSA, Denis Borges. A Propriedade Intelectual no Século XXI: estudos de Direito. Rio de Janeiro: Editora Lumen Juris, 2009.

BITTAR FILHO, Carlos Alberto. Apontamentos sobre a nova lei brasileira de direitos autorais. In: Legislação sobre direitos autorais. 2a. ed. Brasília: Senado Federal, Subsecretaria de Edições Técnicas, 2004.

BRASIL. Decreto no 2.553, de 16 de abril de 1998. Disponível em: http://www.planalto .gov.br/ccivil_03/decreto/D2553.htm. Acesso em: 10 fev 2014.

BRASIL. Lei de Direitos Autorais: Lei no. 9.610, de 19 de fevereiro de 1998. Disponível em: http://www.planalto.gov.br/ccivil_03/leis//9610.htm. Acesso em: 10 fev 2014.

BRASIL. Lei de Inovação: Lei no. Lei 10.973, de 2 de dezembro de 2004. Disponível em: http://www.planalto.gov.br/ccivil_03/_ato2004-2006/2004/lei/l10.973.htm. Acesso em: 10 fev 2014.

BRASIL. Lei da Propriedade Industrial: Lei no. 9.279, de 14 de maio de 1996. Disponível em: http://www.planalto.gov.br/ccivil_03/leis/19279.htm. Acesso em: 10 fev 2014.

BUFRJ - Boletim da Universidade Federal do Rio de Janeiro. Resolução CEPG $\mathbf{n}^{\circ} \mathbf{0 1}$ : BUFRJ $n^{\circ} 19$, de 12 de maio de 2011, p. 10-12. Disponível em: http://www.ufrj.br/docs /boletim/2011/19-2011.pdf. Acesso em: 20 mai 2011.

CNPq - Conselho Nacional de Desenvolvimento Científico e Tecnológico. Resolução Normativa 013/2008. Disponível em: http://www.cnpq.br/web/guest/view/-/journal _content/56_INSTANCE_0oED/10157/24829. Acesso em: 9 abr 2011.

EPO - European Patent Office. Espacenet: patente n BRPI0702968A2. Disponível em: http://worldwide.espacenet.com/publicationDetails/originalDocument?CC=BR\&NR=PI $0702968 A \& K C=A \& F T=D \&$ date $=20090217 \& D B=E P O D O C \&$ locale $=e n \_E P$. Acesso em: 27 mar 2013.

MARTÍNEZ, A. M. Criatividade, personalidade e educação. 3a edição. Trad. Mayra Pinto. São Paulo: Papirus, 2003.

RPI - Revista da Propriedade Industrial. RPI Patente: $n^{\circ} 2127,2093$ e 1859. Disponível em: http: //revistas.inpi.gov.br/rpi/. Acesso em: 10 mar 2013.

VIVEIROS, Luciano. Contraprestação salarial do empregado na invenção. São Paulo: LTr, 2010. 